\title{
Stock Market Bear Regime and Recession: Are They Synchronized?
}

\author{
Thouraya Boudebbous ${ }^{1}$ \\ ${ }^{1}$ High School of Business of Tunis, University of Manouba, Tunisia \\ Correspondence: Thouraya Boudebbous, High School of Business of Tunis, University of Manouba, 2010. \\ Tunisia. E-mail: boudebbous.thouraya@gmail.com
}

Received: November 12, 2014

Accepted: December 1, 2014

Online Published: January 25, 2015

doi:10.5539/ijef.v7n2p261

URL: http://dx.doi.org/10.5539/ijef.v7n2p261

\begin{abstract}
The goal of this work is to study the synchronization of the relationship between bearish stock market fluctuations and periods of economic recession in six developed countries during the period from February 1990 to May 2013.

Hence, first, we have identified cyclical fluctuations of the real economy and stock market by means of an autoregressive Markov regime-switching model, in order to distinguish between boom-bust cycles of economic activity and of the stock market for each country in our sample.

Second, we have tested the degree of synchronization between economic activity and stock market bust cycles by means of the concordance index. Our results confirm the existence of a strong degree of synchronization between bearish stock market periods and periods of economic depression for most countries in our studied sample. Indeed, our results suggest that bearish stock market cycles precede an average of four months before economic recession cycles.
\end{abstract}

Keywords: cycle, synchronization, Markov switching models

\section{Introduction}

The financial system is an integral part of the economy, by contributing to the transfer of funds from entities with a surplus to loss-making entities. The stock market is one of the most important parts of the financial system. Several theorists, for example, Levine and Zervos (1996), and Enisan and Olufisayo (2009) have underlined the positive impact of stock market development on economic growth.

According to Stiglitz et al. (1993), "Stock markets essentially involve the allocation of resources. They can be thought of as the "brain" of the entire economic system, the central locus of decision-making: if they fail, not only will the sector's profits be lower than they would otherwise have been, but the performance of the entire economic system may be impaired.".

In order to understand the mechanisms of price variation on these markets, finance theory has developed the efficient-market hypothesis. According to Walter (1996), the concept of efficiency "claims that quoted prices accurately reflect the underlying economic reality".

The efficient-market hypothesis means that stock market prices should evolve according to the state of the underlying economic environment. In other words, the evolution of macroeconomic fundamentals explains the evolution of stock market prices. However, the financial asset price changes are not necessarily linked to the condition of the situation. This is suggested by the intense boom and bust cycles and periods of disparity in the observed asset values, compared to their fundamental values observed in several financial markets in the world during the last decades (though macroeconomic fluctuations were rather moderate). On the contrary, the dynamics of stock market development seems to have significant repercussions on the dynamics of economic activity. Candelon and Metiu (2011) attribute the strong impact of stock market fluctuation on the real economy to its impact on corporations' balance sheets. Indeed, during periods of euphoria companies tend to increase their financial leverage. However, the decrease of stock prices will cause a decrease in corporations' net value, and therefore in their ability to finance their operations, leading to a slowing down of economic activity.

Few studies have attempted to study the cyclical links between stock markets and the real economy (Estrella \& Mishkin, 1998; Beaudry \& Portier, 2007; Vu, 2014). The pioneering work in this field is that of Hamilton and Lin (1996). They showed that bearish stock market periods precede recession phases of the economic cycle, 
while bullish stock market periods precede expansion phases of the economic cycle. Thus, this suggests that stock market indices are potentially leading indicators of economic activity. Similarly, Kanas and Ioannidis (2010) have observed a robust correlation between real activity and stock market fluctuation in the United Kingdom over the period of 1946 to 2002.

The objective of this study is to examine the synchronization relationship between bearish stock market fluctuations and periods of economic recession in six developed countries. To do so we propose to identify, first, the cyclical fluctuations of the real economy and the stock market by means of Hamilton's (1989) autoregressive Markov regime-switching model. This choice was due to this models' ability to reproduce the NBER business cycle (Darné \& Ferrara, 2011). In effect, these models allow one to consider the asymmetric development of the cycle's boom and bust phases. Second, we propose to test statistically the degree of synchronization between the two cycles by means of the concordance index of Harding and Pagan (2006).

This paper is organized as follows: The first section is an introduction, in the second section we briefly present a review of the existing literature related to the relation between economic activity cycles and stock market cycles. In the third section, we present our methodological approach: our study variables and our economic approaches. In the fourth section we give our study's sample and main data sources, along with a brief descriptive analysis of our data. In the fifth section we describe and discuss our empirical results. The last section is the conclusion.

\section{Literature Review}

The literature has established the existence of a relation between the financial and real spheres. This relation has all the more important these last decades because of the evolution of the financial, economic, and institutional environment in the context of globalization. Among the works that have examined the complex relation between financial cycles, we can note the recent work of Haavio (2012) which suggests that: (i) the interactional relationship between the economic and financial cycles is multidimensional; (ii) the relation between economic and financial cycles is procyclical in nature and financial variables lead the real activity; and (iii) there is a stronger link between economic and financial cycles during periods of recession.

To highlight the nature of the link between the real and the economic spheres, Bordo and Jeanne (2002) have analyzed the extent to which financial disturbances can lead to future recessions. Their results suggest that stock market disturbances can lead to slowing down of economic activity. According to one explanation given by these authors: Bad news on future returns can cause problems in the financial and banking sector through their impact on companies' balance sheets, leading to a decrease in credit, and consequently in consumption and investment, which in turn will negatively affect economic activity. Indeed, during periods of euphoria companies tend to increase their financial leverage. However, if stock prices fall, the net value of companies will also decrease in turn. This will have the effect of reducing the companies' financing capacity. The decrease of investments will negatively affect production and consequently economic activity.

Similarly, Blot et al. (2009) have explored the main channels through which financial shocks can affect the real economy, for a sample of two industrialized countries (France and the United States), during the period 19742009. Their results suggest that a negative shock on the housing market has a negative impact on economic activity.

Furthermore, according to Jermann and Quadrini (2012), stock market disturbances can lead to slowing down of economic activity through investment and employment channels. Indeed, firms which face with stricter financial constraints may cut back on hiring and investment, which can affect negatively the economic activity.

In addition, according to Altissimo et al. (2005, p. 49), "stock market volatility may have direct effects on the real economy through its impact on consumer and business confidence." This can be explained by the fact that stock prices generally reflect the market player's expectations regarding the future company profits, which in turn are closely linked to economic activity. Thus, stock market fluctuations allow the prediction of future economic growth. Consequently, the decrease (vs increase) of financial asset prices can presage bad (vs good) economic outlooks, which will lead to the altering of the risk assessments by the market operators. This will have the effect of reducing (vs augmenting) "their incentive to spend [...] thus affecting consumption and corporate investment" (Altissimo et al., 2005, p.49).

\section{Methodology}

In the following, we will, first, present and define our main variables and then, second, present our two econometric approaches. 


\subsection{Definition of Study Variables}

\subsubsection{Industrial Production Index}

In this study, we have kept the monthly series of the industrial production index $\left(I P I_{i t}\right)$ seasonally adjusted because of the availability of monthly series data. In addition, the study of Anas et al. (2006) has empirically proven the utility of information contained within the IPI for the detection of economic cycle phases.

\subsubsection{Market Returns}

In this study, we have chosen the main market indices adjusted for the dividends for each country in our sample.

All our data sets are analyzed in terms of returns. Thus, for each country, we calculate the market returns $R_{i t}$. This is given by:

$$
R_{i t}=100 * \ln \left(\frac{P_{i t}}{P_{i t-1}}\right)
$$

With $P_{i t}$ is the market index of country $\mathrm{i}$ on date $\mathrm{t}$.

\subsection{Econometric Approach}

\subsubsection{Regime-Switching Model}

In fact, the financial and macroeconomic series, notably stock market returns $\left(R_{i t}\right)$ and the industrial production index $\left(I P I_{i t}\right)$, often tend to change their behavior significantly, particularly during periods of financial or economic disturbances (Hamilton, 2008; Brooks, 2008). In other words, financial series tend to present a "structural break".

The main advantage of regime-switching models is their flexibility, since they can capture average and variance changes in the different regimes. Indeed, these models allow one to take into account the asymmetric development of the boom-bust cycle phases, unlike linear models, which assume that the different cycle phases have identical duration and amplitude. Thus, by allowing movement between different regimes, Markov regime-switching models are capable of capturing the complex dynamics of chronological data sets (Ismail \& Isa, 2008).

With the exception of the United States, which benefited from a reference chronology, maintained by the dating committee of the NBER (National Bureau of Economic Research), for the American business cycle, the other countries in our sample did not enjoy such a chronology. As a result, we have used the Markov regime-switching models (MS) proposed by Hamilton (1989) in order to identify the boom-bust economic cycle phases for each country in our studied sample. Several works in the empirical literature use these models to identify the different phases of the economic cycle; we may justly cite the work of Grégoir and Lenglart (2000), Artis et al. (2004), and Layton and Smith (2007).

In addition, Turner et al. (1989) have underlined the usefulness of these models in capturing the behavior of regime-switching in the average and variance of market return series.

Hamilton's model is defined as follows: We define the process $\left(y_{t}\right) t$ as an MS(2) process if it verifies the following equations; in the case of an $\operatorname{AR}(\mathrm{p})$ process, is called a $\operatorname{MS}(2)-\operatorname{AR}(\mathrm{p})$ process:

$$
\begin{aligned}
& y_{t}=\mu_{S_{t}}+\alpha_{I S_{t}} y_{t-1}+\ldots+\alpha_{p S_{t}} y_{t-p}+\varepsilon_{t} \quad \varepsilon_{t} \sim \operatorname{iid}\left(0, \sigma_{i}^{2}\left(S_{t}\right)\right) \\
& S_{t}=j, S_{t-i}=i \quad i, j \in 1,2
\end{aligned}
$$

With $y_{t}$ being the variable whose temporal evolution we want to determine; $\mu_{\mathrm{s}_{\mathrm{t}}}$ represents the rate of medium growth corresponding to the state $\mathrm{S}_{\mathrm{t}}$ and $\varepsilon_{\mathrm{t}}$ is white noise of variance $\sigma_{i}{ }^{2}\left(\mathrm{~S}_{\mathrm{t}}\right)$ which can be considered a state of dependence.

For all $t$, the unobservable variable $S_{t}$ has a value of 1 when the state is in regime 1 and a value of 2 when the state is in regime 2. State $\mathrm{S}_{\mathrm{t}}$ follows a two-regime Markov chain characterized by the following property:

$$
p_{i j}=P\left(S_{t}=j \mid S_{t-1}=i\right), \quad \sum_{1}^{N} p_{i j}=1 \quad \forall i, j \in\{1,2\}
$$

Where $\left(p_{i j}\right) i, j$ are the transition probabilities. These last allow one to measure the probability of changing from one regime to another. Similarly, $\mu\left(s_{t}\right)$ and $\sigma^{2}\left(s_{t}\right)$ represent, respectively, the conditional average and conditional variance, depending on the state of nature.

Markov regime-switching models facilitate the identification of different regimes (or states) in the evolution of a variable $\left(y_{t}\right)$. 
The estimation of model parameters consists of the using of the maximum likelihood estimation, to determine the whole of the model parameters. According to Krolzig (2001), and Hamilton (1989), these parameters allow one to get the smoothed and filtered probabilities of the unobserved variable $s_{t}$. The determination of smoothed and filtered probabilities associated with each regime allows the dating of changeover points from one regime to another.

\subsubsection{Statistical Index of Concordance}

Different methods have been used in the literature to test the concordance or synchronization between two financial and/or economic series, notably the concordance index of Harding and Pagan (2006). This index is given by the following regression:

$$
\frac{S_{j, t}}{\sigma_{S_{j}}}=\vartheta+\delta_{s}\left(\frac{S_{i, t-l}}{\sigma_{S_{i}}}\right)+\varepsilon_{t}
$$

With, $S_{j, t}$ and $S_{i, t}$ being, respectively, the binary variables indicative of the cycle state of both the economic activity, and the stock market. They are based on smoothed recession-regime probabilities derived from the Markov regime-switching model. They are defined as follows:

$$
\begin{gathered}
S_{j, t}=\left\{\begin{array}{r}
1 \text { if the smoothed probabilities of } I P I_{i, t}>0.5 \\
0 \text { otherwise }
\end{array}\right. \\
S_{i, t}=\left\{\begin{array}{c}
1 \text { if the smoothed probabilities of } R_{i, t}>0.5 \\
0 \text { otherwise }
\end{array}\right.
\end{gathered}
$$

$l$ is the index that takes into account the delay of variable $S_{i, t}$. We consider various delay orders with a maximum 24-month delay, as Candelon and Metiu (2011) have suggested in their work: $l=\{0 ; 2 ; 4 ; 6 ; 8 ; 12 ; 16$; $20 ; 24\} ; \sigma_{S_{j}}$ and $\sigma_{S_{i}}$ are the standard deviations, respectively, of $S_{j, t}$ and $S_{i, t} ; \vartheta$ is the constant; and $\varepsilon_{t}$ is the error term.

\section{Sample, Data Sources and Properties}

Our sample consists of six developed countries, namely: Germany, Austria, Greece, Ireland, the Netherlands, and the United States.

The data relating to the industrial production index (IPI) are derived from the database of the Organization for Economic Co-operation and Development (OECD). In addition, the data relating to the main stock market indices are derived from the Bloomberg database.

In Table 1 we have presented the main stock market indices chosen by this study.

Table 1. Stock market indices

\begin{tabular}{lc}
\hline Country & Stock Market Index \\
\hline $\mathrm{M}$ & DAX \\
Austria & WBI \\
Greece & ASE \\
Ireland & ISEQ \\
Netherlands & AEX \\
United-States & S\&P500 \\
\hline
\end{tabular}

Consequently, the study is based on 6 advanced economies, on monthly data from the period February 1990 to June 2013 (281 observations).

The IPI is analyzed in terms of log. Indeed, according to Darné and Ferrara (2011), the economic cycle as defined by Burns and Mitchell (1946) refers to the (log-) level of the series. 
Table 2. Descriptive statistics of the industrial production index (IPI)

\begin{tabular}{lcccccc}
\hline & Germany & Austria & Greece & Ireland & Netherlands & United States \\
\hline Mean & 1.974324 & 1.92373 & 1.951079 & 1.806977 & 1.97012 & 1.940508 \\
Median & 1.967886 & 1.9454 & 1.947277 & 1.928233 & 1.98174 & 1.969684 \\
Maximum & 2.07511 & 2.08463 & 2.023153 & 2.089532 & 2.05751 & 2.024111 \\
Minimum & 1.889014 & 1.74718 & 1.850371 & 1.350254 & 1.86703 & 1.800657 \\
Std. Dev. & 0.051265 & 0.11201 & 0.045739 & 0.240813 & 0.04732 & 0.069277 \\
Skewness & 0.377487 & -0.128 & -0.13337 & -0.63604 & -0.23881 & -0.77802 \\
Kurtosis & 1.94888 & 1.51817 & 1.692731 & 1.81605 & 1.83683 & 2.151951 \\
Jarque-Bera & 19.67937 & 26.5709 & 20.91624 & 35.48436 & 18.5778 & 36.90057 \\
Observations & 281 & 281 & 281 & 281 & 281 & 281 \\
\hline
\end{tabular}

The results of the descriptive statistics of the IPI are given in Table 2. We can see that for the group of countries in our sample, our data sets are asymmetric. Most of these series have a fat left tail (Skewness coefficient $<0$ ), that is to say, most of the values are concentrated to the right of the average, with extreme values to the left. Similarly, most of these series present a platykurtic distribution (kurtosis coefficient $<3$ ), which means that the distribution is flatter than a normal distribution, with a larger peak and a larger probability, in order for the extreme values to be less than a normal distribution, and the values represent the largest spread around the average. In addition, the results of the Jarque-Bera normality test require us to reject the normality hypothesis for the group of our data sets $\left(\mathrm{JB}>\chi_{0.95}^{2}(2)\right)$.

Table 3. Descriptive statistics of market index returns

\begin{tabular}{lcccccc}
\hline & Germany & Austria & Greece & Ireland & Netherlands & United States \\
\hline Mean & 0.524544 & 0.198327 & 0.160093 & 0.27356 & 0.354129 & 0.564191 \\
Median & 1.314959 & 0.77251 & 0.351069 & 0.97875 & 1.163989 & 1.061759 \\
Maximum & 19.37378 & 16.07278 & 40.96699 & 17.8253 & 14.56889 & 10.57895 \\
Minimum & -29.33269 & -39.4592 & -32.673 & -23.5823 & -22.6216 & -18.5637 \\
Std. Dev. & 6.393087 & 6.095511 & 9.833509 & 5.86594 & 5.771527 & 4.327333 \\
Skewness & -0.925675 & -1.37247 & 0.354044 & -0.73962 & -0.95493 & -0.79533 \\
Kurtosis & 5.563888 & 9.303853 & 5.458196 & 4.79479 & 5.172516 & 4.651192 \\
Jarque-Bera & 117.0952 & 553.4917 & 76.62067 & 63.3357 & 97.9684 & 61.54629 \\
Observations & 281 & 281 & 281 & 281 & 281 & 281 \\
\hline
\end{tabular}

The results of the descriptive statistics for the stock returns are shown in Table 3 According to the results of our descriptive statistics, we note that for the whole of the countries in our study, our data sets are asymmetric. Similarly, most of these series present a thick left tail (skewness coefficient $<0$ ) and are leptokurtic (kurtosis coefficient $>3$ ), which means that the distribution is sharper than a normal distribution, with values concentrated around the average and the thick tails, and consequently a strong probability for the extreme values. In addition, the results of the Jarque-Bera normality test require us to reject the normality hypothesis for the group of our data sets $\left(\mathrm{JB}>\chi_{0.95}^{2}(2)\right)$.

Table 4. Stationary test

\begin{tabular}{lcc}
\hline & \multicolumn{2}{c}{ ADF } \\
\hline Germany & (IPI) & Rendements $^{\mathbf{1}}$ \\
Austria & -6.87294 & -15.71872 \\
Greece & -16.63185 (ii) & -11.80768 \\
Ireland & -14.37299 & -14.15289 \\
Netherlands & $-13.76798(\mathrm{i})$ & -13.26059 \\
United-States & -14.51592 & -14.92552 \\
\hline
\end{tabular}

Note. Most data set regressions for the group of countries in our sample, most data sets only include an interception. The symbol (i) indicates that the data sets include a tendency and an interception; while the symbol (ii) indicates that the data sets contain an interception. The critical value of $95 \%$ for regressions with a tendency and interception is -3.43 , for regressions with an interception, it is -2.88 , and for regressions without tendency and without interception it is -1.94 . 
Furthermore, the standard tests for unit roots (Augmented-Dickey-Fuller) are given in Table 4. The results of this test indicate that our six IPI data sets are non-stationary in level, which justifies the move to the first difference, first difference stationary D (IPI). On the other hand, the tests' results show that our six market returns are stationary in level.

\section{Empirical Results}

We recall that the goal of this work is to study the synchronization relation between the fluctuations of the bearish stock markets and the economic recession phases in six developed countries. The implementation of the MS model requires the following hypotheses: (i) We assume that the autoregressive order (p) is 4 for the industrial production index and 1 for market returns. This choice was motivated by the respective correlograms of our data sets; and (ii) we assume the existence of two regimes $(K=2)$ in order to respect the characteristics of the classical cycle (boom-bust).

The estimation results of the MS(2)-AR(P) model for each of our data sets and for each country in the study are given in Tables 5 and 6 .

Given the results of these tables, we note that each of the two regimes identified for the industrial production index and the market returns have a clear economic interpretation.

(i) Industrial production index

According to table 5, we note that for most of our data sets the autoregressive order coefficients $\left(\alpha_{1}, \alpha_{2}, \beta_{1}, \beta_{2}, \varphi_{1}\right.$, $\left.\varphi_{2}, \rho_{1}, \rho_{2}\right)$ are significant.

Table 5. Estimation results of the industrial production index by model MS(2)-AR(4)

\begin{tabular}{|c|c|c|c|c|c|c|}
\hline & Germany & Austria & Greece & Ireland & Netherlands & United States \\
\hline$\mu_{1}$ & $\begin{array}{c}-0.0085^{* * *} \\
(0.0012)\end{array}$ & $\begin{array}{c}0.0063^{* * *} \\
(0.0010)\end{array}$ & $\begin{array}{c}0.0048 * * * \\
(0.0012)\end{array}$ & $\begin{array}{c}0.0086^{* * *} \\
(0.0022)\end{array}$ & $\begin{array}{c}-0.0079 * * \\
(0.0027)\end{array}$ & $\begin{array}{c}-0.0016 * * * \\
(0.0001)\end{array}$ \\
\hline$\mu_{2}$ & $\begin{array}{c}0.0020^{* * *} \\
(0.0004)\end{array}$ & $\begin{array}{c}-0.0073 * * * \\
(0.0022)\end{array}$ & $\begin{array}{c}-0.0066^{* * *} \\
(0.0011)\end{array}$ & $\begin{array}{c}0.0127 * * * \\
(0.0049)\end{array}$ & $0.0037 *(0.0020)$ & $\begin{array}{c}0.0029 * * * \\
(0.0007)\end{array}$ \\
\hline$\sigma_{1}^{2}$ & $\begin{array}{l}0.0238 * * * \\
(0.0019)\end{array}$ & $\begin{array}{l}0.0127 * * * \\
(0.0008)\end{array}$ & $\begin{array}{c}0.0130 * * * \\
(0.0009)\end{array}$ & $\begin{array}{c}0.0540^{* * *} \\
(0.0037)\end{array}$ & $\begin{array}{c}0.0262 * * * \\
(0.0019)\end{array}$ & $\begin{array}{c}0.0066^{* * * *} \\
(0.0008)\end{array}$ \\
\hline$\sigma_{2}^{2}$ & $\begin{array}{c}0.0118 * * * \\
(0.0006)\end{array}$ & $\begin{array}{c}0.0238 * * * \\
(0.0030)\end{array}$ & $\begin{array}{c}0.0407 * * * \\
(0.0018)\end{array}$ & $\begin{array}{c}0.0238^{* * * *} \\
(0.0040)\end{array}$ & $\begin{array}{c}0.0095 * * * \\
(0.0018)\end{array}$ & $\begin{array}{c}0.0043^{* * *} \\
(0.0002)\end{array}$ \\
\hline$\alpha_{1}$ & $\begin{array}{c}0.5492 * * * \\
(0.1165)\end{array}$ & $\begin{array}{c}-0.4218 * * * \\
(0.1004)\end{array}$ & $\begin{array}{c}-0.4352 * * * \\
(0.0806)\end{array}$ & $\begin{array}{c}-0.7002 * * * \\
(0.0906)\end{array}$ & $\begin{array}{c}-0.6038 * * * \\
(0.0989)\end{array}$ & $\begin{array}{c}0.8740 * * * \\
(0.3214)\end{array}$ \\
\hline$\alpha_{2}$ & $\begin{array}{c}-0.3271 * * * \\
(0.0668)\end{array}$ & $\begin{array}{c}-0.2681 * * * \\
(0.1579)\end{array}$ & $\begin{array}{c}-0.7345 * * * \\
(0.1873)\end{array}$ & $\begin{array}{c}-0.3733 * * * \\
(0.0974)\end{array}$ & $-0.1903(0.1375)$ & $\begin{array}{c}-0.2274 * * * \\
(0.0602)\end{array}$ \\
\hline$\beta_{1}$ & $0.3757(0.2648)$ & $\begin{array}{c}-0.1627 * * * \\
(0.0719)\end{array}$ & $\begin{array}{c}-0.1531 * * \\
(0.0773)\end{array}$ & $\begin{array}{c}-0.3746^{* * * *} \\
(0.1150)\end{array}$ & $\begin{array}{c}-0.4768 * * * \\
(0.1300)\end{array}$ & $-0.3076^{*}(0.1880)$ \\
\hline$\beta_{2}$ & $-0.0095(0.0767)$ & $\begin{array}{c}-0.4794 * * * \\
(0.1730)\end{array}$ & $\begin{array}{c}-0.4424 * * \\
(0.2124)\end{array}$ & $-0.0241(0.0666)$ & $-0.0499(0.1122)$ & $\begin{array}{c}0.1570 * * * \\
(0.0562)\end{array}$ \\
\hline$\varphi_{1}$ & $0.1168(0.3062)$ & $-0.0658(0.0641)$ & $\begin{array}{c}-0.2276^{* * *} \\
(0.0644)\end{array}$ & $\begin{array}{c}-0.1371 * * * \\
(0.1707)\end{array}$ & $-0.2093(0.1385)$ & $0.1642 *(0.0964)$ \\
\hline$\varphi_{2}$ & $\begin{array}{c}0.2188 * * * \\
(0.0659)\end{array}$ & $\begin{array}{c}0.5475^{* * *} \\
(0.1945)\end{array}$ & $-0.2711(0.2048)$ & $\begin{array}{c}-0.2748 * * \\
(0.1143)\end{array}$ & $-0.1155 *(0.0577)$ & $0.1684 * *(0.0768)$ \\
\hline$\rho_{1}$ & $-0.3226(0.3568)$ & $0.0539(0.0648)$ & $-0.0824(0.0630)$ & $-0.0967(0.0937)$ & $0.1654(0.1173)$ & $0.0359(0.1529)$ \\
\hline$\rho_{2}$ & $\begin{array}{c}0.1677 * * * \\
(0.0740)\end{array}$ & $0.0417(0.1324)$ & $-0.1378(0.1963)$ & $-0.0684(0.0502)$ & $\begin{array}{c}-0.1267 * * * \\
(0.0441)\end{array}$ & $-0.0359(0.0898)$ \\
\hline $\mathbf{p}_{11}$ & 0.91 & 0.90 & 0.87 & 0.85 & 0.79 & 0.86 \\
\hline $\mathbf{p}_{22}$ & 0.99 & 0.62 & 0.68 & 0.85 & 0.79 & 0.97 \\
\hline Regime 1 & 11.60 & 10.13 & 7.59 & 6.51 & 4.88 & 6.95 \\
\hline Regime 2 & 194.25 & 2.63 & 3.12 & 6.89 & 4.70 & 31.63 \\
\hline Log likelihood & -819.2977 & -749.7134 & -672.5831 & -498.3577 & -705.0765 & -1070.8629 \\
\hline
\end{tabular}

Similarly, with the exceptions of Austria and Greece, the expected averages for regime $1\left(\mu_{1}\right)$ are inferior to the expected averages of regime $2\left(\mu_{2}\right)$. Thus, regime 2 allows one to capture the behavior of the economy during its growth phase, and conversely, regime 1 allows one to capture the fluctuations of economic activity during its 
recession phase.

For most of our data sets, the recession phases are characterized by strong volatility and weak average growth in the variation of the industrial production index, since the volatility of the depression regime $\left(\sigma^{2}{ }_{1}\right)$ is superior to the volatility of the expansion phase $\left(\sigma_{2}^{2}\right)$.

Similarly, for most of our data sets, with the exception of Ireland, the conditional averages of the bearish regime $\left(\mu_{1}\right)$ are characterized by negative signs. This indicates that for most of the countries in our samples, the variation of the industrial production index monthly average during periods of recession decrease around -0.0085 and 0.0016 . Similarly, this variation during the growth period is around 0.0063 and 0.0127 .

Furthermore, the probabilities of remaining in the expansion regime $\left(p_{22}\right)$ are higher than the probabilities of remaining in the recession regime $\left(p_{11}\right)$ for the majority of our data sets, except for the Netherlands and Ireland, which present a probability of staying in the recession regime equal to the probability of staying in the expansion regime. The values of $p_{11}$ are between 0.79 and 0.91 and those of $p_{22}$ are between 0.62 and 0.99 . The expected durations of remaining in the boom regime vary between 2.63 and 194.25 months and the expected durations of staying in a depression regime are between 4.88 and 11.60 months. This implies that most of our data sets remain in the growth regimes longer than in the recession regime.

(ii) Market returns

According to table 6 , we note that for most of our data sets the coefficients of autoregressive orders $\left(\alpha_{1}, \alpha_{2}, \beta_{1}\right.$, $\beta_{2}$ ), are significant.

Table 6. Estimation results of market returns by model MS(2)-AR(2)

\begin{tabular}{|c|c|c|c|c|c|c|}
\hline & Germany & Austria & Greece & Ireland & Netherlands & United States \\
\hline \multirow[b]{2}{*}{$\mu_{1}$} & $0.0185^{* * *}$ & $-0.0206^{* *}$ & $-0.0436^{* * *}$ & & $-0.0296^{* *}$ & $0.0109 * * *$ \\
\hline & $(0.0043)$ & $(0.0105)$ & $(0.0018)$ & $-0.0186 *(0.0110)$ & $(0.0147)$ & $(0.0028)$ \\
\hline \multirow[b]{2}{*}{$\mu_{2}$} & & $0.0704 * * *$ & & & $0.0646 * * *$ & $-0.0094 * * *$ \\
\hline & $-0.0212 *(0.0124)$ & $(0.0162)$ & $0.0104 * *(0.0048)$ & $0.0118 * * *(0.0036)$ & $(0.0106)$ & $(0.0003)$ \\
\hline \multirow{2}{*}{$\sigma_{1}^{2}$} & $0.0401 * * *$ & $0.0870^{* * *}$ & $0.1136^{* * *}$ & & $0.0893 * * *$ & $0.0220 * * *$ \\
\hline & $(0.0023)$ & $(0.0099)$ & $(0.0082)$ & $0.0819 * * *(0.0065)$ & $(0.0073)$ & $(0.0072)$ \\
\hline \multirow{2}{*}{$\sigma_{2}^{2}$} & $0.0944 * * *$ & $0.0395 * * *$ & $0.0465 * * *$ & & $0.0389 * * *$ & $0.0532 * * *$ \\
\hline & $(0.0073)$ & $(0.0023)$ & $(0.0073)$ & $0.0396 * * *(0.0021)$ & $(0.0021)$ & $(0.0064)$ \\
\hline \multirow[b]{2}{*}{$\alpha_{1}$} & & $0.2989 * * *$ & & & & $-0.1115 * * *$ \\
\hline & $-0.1178 *(0.0708)$ & $(0.1058)$ & $0.1576 * *(0.0712)$ & $0.1896 *(0.1107)$ & $0.0836(0.1599)$ & $(0.0036)$ \\
\hline \multirow[b]{2}{*}{$\alpha_{2}$} & $0.0614 * * *$ & $0.2704 * * *$ & & & & $0.0936(0.0056)$ \\
\hline & $(0.0021)$ & $(0.0662)$ & $0.1299(0.1010)$ & $0.1283 *(0.0730)$ & $-0.0551(0.0749)$ & \\
\hline $\mathbf{p}_{11}$ & 0.94 & 0.92 & 0.99 & 0.93 & 0.81 & 0.98 \\
\hline $\mathbf{p}_{22}$ & 0.84 & 0.98 & 0.97 & 0.97 & 0.95 & 0.98 \\
\hline Regime 1 & 15.44 & 12.04 & 74.40 & 14.36 & 5.35 & 42.65 \\
\hline Regime 2 & 6.20 & 40.78 & 35.86 & 39.71 & 19.12 & 45.28 \\
\hline Log likelihood & -404.2324 & -434.413 & -281.0931 & -429.7063 & -433.5285 & -512.3056 \\
\hline
\end{tabular}

Similarly, with the exception of Germany and the United States, the expected averages of regime $2\left(\mu_{2}\right)$ are superior to the expected averages of regime $1\left(\mu_{1}\right)$. Thus, regime 2 allows one to capture the behavior of the stock market during its bullish phase, and reciprocally regime 1 allows one to capture the fluctuations of the stock market during these bearish phases.

For most of our data sets, the bearish periods were characterized by strong volatility and weak average expected stock market growth. Indeed, we note that the volatility of the bullish regime $\left(\sigma_{2}^{2}\right)$ is inferior to the volatility of the bearish regime $\left(\sigma_{1}^{2}\right)$.

In addition, for the group of our data sets, the conditional averages of the bearish regime are characterized by negative signs. This indicates that the average monthly market returns during bearish phases tend to reach their lowest points around -0.0436 and -0.0094 . Conversely, the average monthly market returns during bullish phases tend to peak at around 0.0104 and 0.0704 .

Furthermore, the probabilities of staying in the bullish regime $\left(p_{22}\right)$ are higher than the probabilities of staying in the bearish regime $\left(p_{11}\right)$ for most of our data set, except for the ASE (Greece) and S\&P500 (United States) 
indices that present probabilities of staying in the bullish regime that are less than or equal to those of staying in the bearish regime. The values of $p_{11}$ are around 0.81 and 0.99 and those of $p_{22}$ are around 0.84 and 0.98 . Thus, the expected durations of staying in the bullish regime vary between 19.12 and 40.78 months, and the expected durations of staying in the bearish regime are around 5.35 and 74.40 months. This implies that most of our data sets remain in bullish regimes longer than in regime 2.

Thus, we can conclude, according to the set of our results that only extreme events can cause a real economy and the stock market to migrate from an expansion or bullish regime to a recession or bearish one.

In addition to the expected average, the expected volatility and expected duration of each regime (Expansion/Recession), the Ms(2)-AR(P) model has the advantage of providing the smoothed and filtered probabilities of the unobserved variable $s_{t}$ associated with each of the two regimes (high/low) at time $t$. Furthermore, this has allowed us to identify the changeover points of a regime to another in our data series, and more specifically the changeover points towards bearish regimes that we illustrate in Figures 1.1 to 1.6 for each country in our sample.
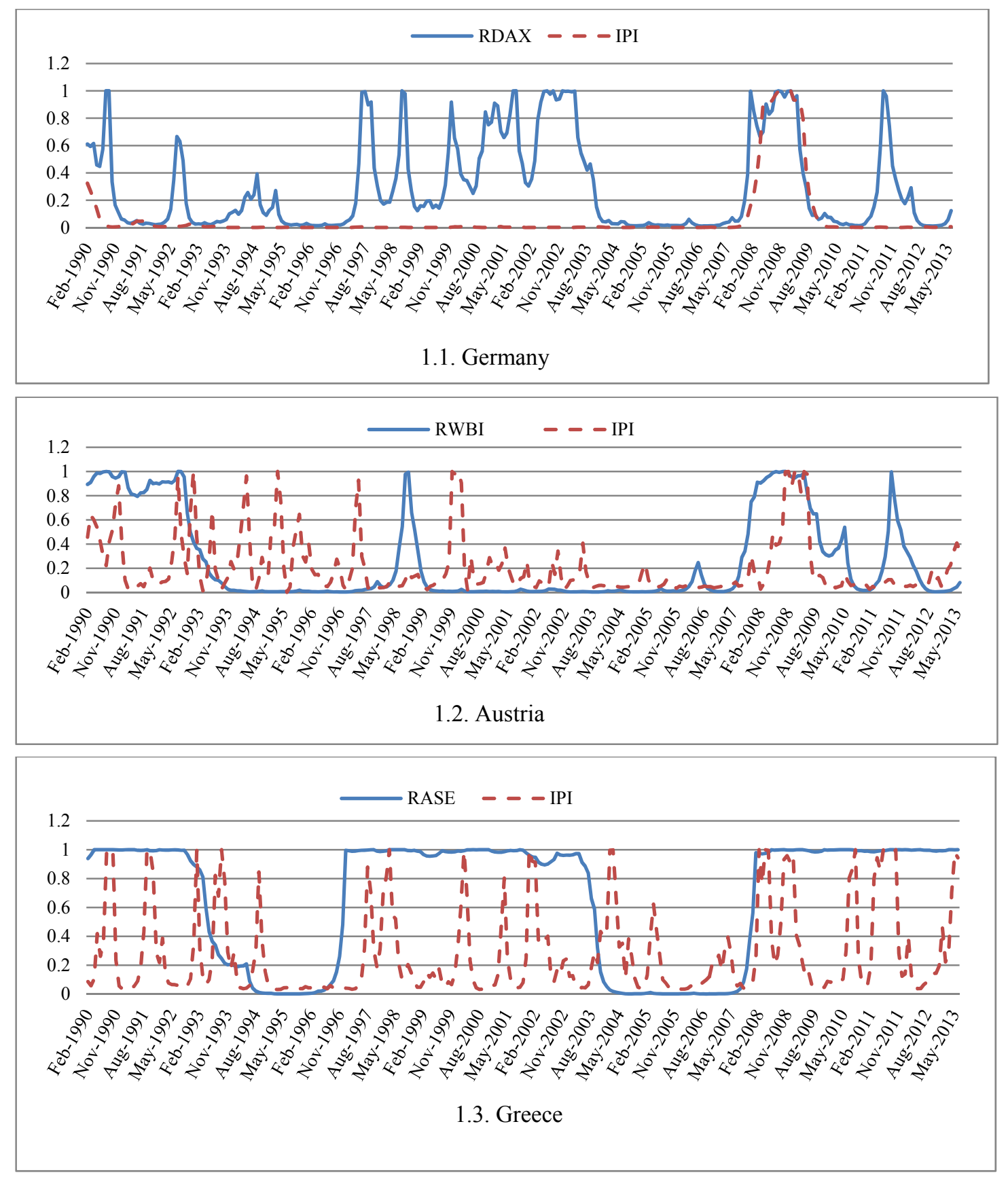

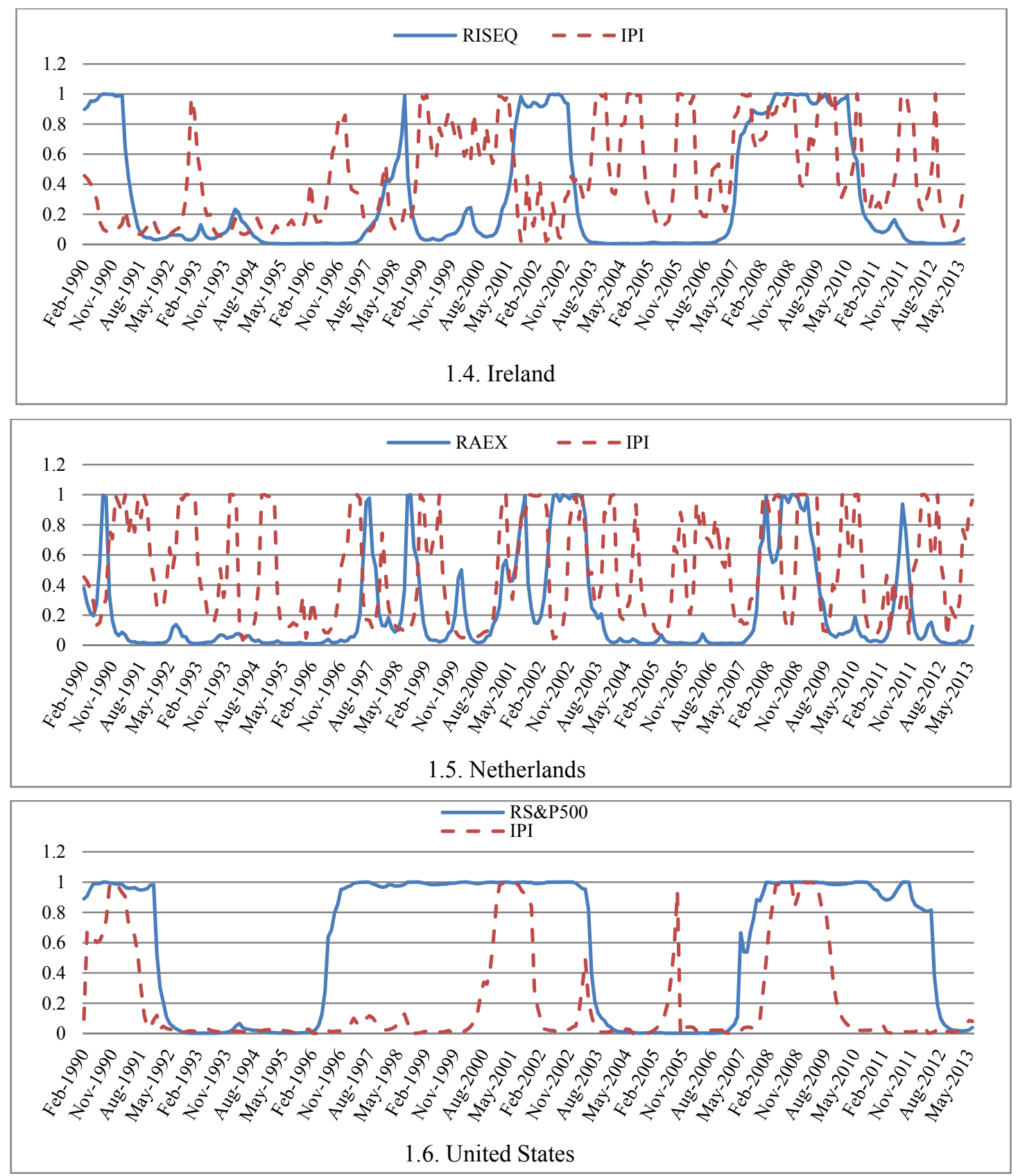

Figure 1. Link between recession and stock market bear over the period of February 1990 to June 2013

According to Figure 1.6, we note that for the United States, the dates of slowing down of economic activity identified by means of this approach coincide for the most part with the recession dates identified by the NBER committee.

Similarly, according to Figures 1.1 to 1.6 we note that for the group of countries in our study, the bearish stock market phases often coincide or precede periods of economic slowing down. This implies the existence of a strong correlation between the peaks of the stock market bear regimes and periods of recession.

In order to underline the correlation between the peaks of the bearish stock markets and periods of recession, for each country in our sample we have used the statistical concordance index of Harding and Pagan (2006). The results of this test are given in Table 7. 
Table 7. Results of the concordance test

\begin{tabular}{|c|c|c|c|c|}
\hline Country & $c$ & $l(2)$ & $l(4)$ & $l(6)$ \\
\hline & $7.684507 * * *$ & $6.560150 * * *$ & $5.240082 * * *$ & $2.849042 * * *$ \\
\hline \multirow[t]{2}{*}{ Germany } & $(0.260796)$ & $(0.229448)$ & $(0.188866)$ & $(0.107702)$ \\
\hline & $5.593148 * * *$ & $5.042598 * * *$ & $3.754112 * * *$ & $2.592896 * * *$ \\
\hline \multirow[t]{2}{*}{ Austria } & $(0.218347)$ & $(0.201378)$ & $(0.155547)$ & $(0.110965)$ \\
\hline & $3.547399 * * *$ & $3.073184 * * *$ & $2.713372 * * *$ & $2.618448 * * *$ \\
\hline \multirow[t]{2}{*}{ Greece } & $(0.148016)$ & $(0.127314)$ & $(0.113056)$ & $(0.109737)$ \\
\hline & 1.506626 & $2.249788 * *$ & $3.201721 * * *$ & $4.077258 * * *$ \\
\hline \multirow[t]{2}{*}{ Ireland } & $(0.076157)$ & $(0.114522)$ & $(0.163215)$ & $(0.207936)$ \\
\hline & 1.064798 & 0.677382 & 0.657100 & 0.912788 \\
\hline \multirow[t]{2}{*}{ Netherlands } & $(0.070290)$ & $(0.044698)$ & $(0.043441)$ & $(0.060523)$ \\
\hline & $7.939041 * * *$ & $7.750438 * * *$ & $7.531758 * * *$ & $7.275801 * * *$ \\
\hline United-States & $(0.308235)$ & $(0.303486)$ & $(0.297836)$ & $(0.290772)$ \\
\hline \multirow[t]{2}{*}{ Country } & $l(8)$ & $l(12)$ & $l(16)$ & $l(24)$ \\
\hline & $1.921412 *$ & 0.361466 & $-2.244484 * *$ & $-2.857316^{* * *}$ \\
\hline \multirow[t]{2}{*}{ Germany } & $(0.073949)$ & $(0.014054)$ & $(-0.087339)$ & $(-0.113697)$ \\
\hline & $1.720241 *$ & 1.194109 & 0.915898 & -1.576136 \\
\hline \multirow[t]{2}{*}{ Austria } & $(0.075632)$ & $(0.053680)$ & $(0.042915)$ & $(-0.080551)$ \\
\hline & $2.653123 * * *$ & $2.597082 * * *$ & $2.308289 * * * *$ & -1.087894 \\
\hline \multirow[t]{2}{*}{ Greece } & $(0.111744)$ & $(0.109989)$ & $(0.098800)$ & $(-0.046308)$ \\
\hline & $4.652852 * * *$ & $5.132461 * * *$ & $6.496683 * * *$ & $5.930282 * * *$ \\
\hline \multirow[t]{2}{*}{ Ireland } & $(0.238460)$ & $(0.264086)$ & $(0.335031)$ & $(0.309468)$ \\
\hline & 0.529796 & -0.135951 & 0.151639 & $-2.315489 * *$ \\
\hline \multirow[t]{2}{*}{ Netherlands } & $(0.036015)$ & $(-0.009256)$ & $(0.010372)$ & $(-0.158434)$ \\
\hline & $6.828756^{* * *}$ & $6.245382 * * *$ & $4.788466^{* * *}$ & 0.710445 \\
\hline United-States & $(0.276960)$ & $(0.257699)$ & $(0.205095)$ & $(0.032515)$ \\
\hline
\end{tabular}

Note. Significant t-statistic at the threshold of $* * * 1 \%, * * 5 \%$ and $* 10 \%$; () Coefficients.

These results confirm the existence of a strong degree of synchronization between stock market bearish phases and periods of economic depression for most of the countries in our sample with the exception of the Netherlands. In addition, our results suggest, following the introduction of the lag, the existence of a procyclical relation between bearish stock market phases and economic recession for most of the countries in our study with the exception of the Netherlands. However, when we consider a lag greater than 12 months, the relation between the bearish stock market phases and the phases of economic recession becomes counter-cyclical in some countries, namely: Germany and the Netherlands. This suggests that stock market turbulence has a short-term effect on economic activity, on a time horizon lasting no longer than 8 months. Thus, the bearish stock market cycles have a tendency to develop prior to cycles of economic recessions by four months on average. This is consistent with the work of Candelon and Metiu (2011) who argue that fluctuations in bearish stock market trends precede economic cycles by around six months.

\section{Conclusion}

This document provides a new perspective on the cyclical links between bearish markets and economic activity, by studying the synchronization relation between bearish fluctuations of stock markets and periods of economic recession in six developed countries. Thus, in the framework of this study we can identify the cyclical fluctuations of the real economy and the stock market by means of the autoregressive Markov regime-switching model of Hamilton (1989) on the period February 1990 to June 2013, in order to distinguish boom-bust cycles of economic activity and of the stock market for each country in our sample. Additionally, we have statistically tested the degree of synchronization between the bust cycles of economic activity and of the stock market by means of the concordance index of Harding and Pagan (2006).

Our results confirm the existence of a strong degree of synchronization between bearish stock market periods and periods of economic depression for most of the countries in our studied sample, with the exception of the Netherlands. Indeed, the bearish stock market cycles seem to appear around four months on average prior to the economic recession cycles. This implies that the transfer of shocks from the stock market to the real economy is significant and that the interdependence relation between these two entities is considerable. 
This study is not exhaustive. A possible extension to this study would be to test the dynamics of the short-term and long-term interaction between the stock market and economic activity.

\section{References}

Altissimo, F., Georgiou, E., Sastre, T., Valderrama, M. T., Sterne, G., Stocker, M., \& Willman, A. (2005). Wealth and asset price effects on economic activity. Occasional paper series. European Central Bank, Germany.

Anas, J., Billio, M., Ferrara, L., \& LoDuca, M. (2006). A turning point chronology for the Euro-zone. In G. L. Mazzi \& G. Savio (Eds.), Growth and Cycle in the Euro zone (pp. 261-274). Palgrave MacMillan.

Artis, M., Krolzig, H. M., \& Toro, J. (2004). The European business cycle. Oxford Economic Papers Volume, 56(1), 1-44. http://dx.doi.org/10.1093/oep/56.1.1

Beaudrya, P., \& Portier, F. (2007). When can changes in expectations cause business cycle fluctuations in neo-classical settings? Journal of Economic Theory, 135(1), 458-477. http://dx.doi.org/10.1016/j.jet.2006.06.009

Blot, C., Le Bayon, S., Lemoine, M., \& Levasseur, S. (2009). De la crise financière à la crise économique: Une analyse comparative France-États-Unis. Revue de l'OFCE, 3(110), 255-281. http://dx.doi.org/10.3917/reof.110.0225

Bordo, M. D., \& Jeanne, O. (2002). Monetary Policy and Asset Prices: Does 'Benign Neglect' Make Sense? International Finance, 5(2), 139-164. http://dx.doi.org/10.1111/1468-2362.00092

Brooks, C. (2008). Introductory Econometrics for Finance (2nd ed.). Cambridge University Press. http://dx.doi.org/10.1017/CBO9780511841644

Burns, A. F., \& Mitchell, W. C. (1946). Measuring Business Cycles. In A. F. Burns \& W. C. Mitchell (Eds.), Dating Specific and Business Cycles (Vol. 46, pp. 56-114). National Bureau of Economic Research.

Candelon, B., \& Metiu, N. (2011). Linkages between Stock Market Fluctuations and Business Cycles in Asia. In Y. W. Cheung, V. Kakkar \& G. Ma (Eds.), He Evolving Role of Asia in Global Finance (Frontiers of Economics and Globalization) (Vol. 9, pp. 24-49). Emerald Group Publishing Limited. http://dx.doi.org/10.1108/S1574-8715(2011)0000009007

Darné, O., \& Ferrara, L. (2011). Identification of Slowdowns and Accelerations for the Euro Area Economy. $\begin{array}{lllll}\text { Oxford Bulletin of Economics } & \text { and }\end{array}$ http://dx.doi.org/10.1111/j.1468-0084.2010.00617.x

Enisan, A. A., \& Olufisayo, A. O. (2009). Stock market development and economic growth: Evidence from seven sub-Sahara African countries. Journal of Economics and Business, 61(2), 162-171. http://dx.doi.org/10.1016/j.jeconbus.2008.05.001

Estrella, A., \& Mishkin, F. S. (1998). Predicting U.S. Recessions: Financial Variables as Leading Indicators. The Review of Economics and Statistics, 80(1), 45-61. http://dx.doi.org/10.1162/003465398557320

Grégoir, S., \& Lenglart, F. (2000). Measuring the Probability of a Business Cycle Turning Point by Using a Multivariate Qualitative Hidden Markov Model. Journal of Forecasting, 19, 39-60. http://dx.doi.org/10.1002/(SICI)1099-131X(200003)19:2<81::AID-FOR734>3.0.CO;2-L

Haavio, M. (2012). Financial Cycles and Business Cycles: Some Stylized Facts. Monetary Policy and Research, $4(1), 3-20$.

Hamilton, H. D. (2008). Regime-Switching Models. In S. N. Durlauf \& L. E. Blume (Eds.), The Palgrave Dictionary of Economics (2ed. Vol. 1, pp. 1-276). Palgrave Macmillan.

Hamilton, J. D. (1989). A new approach to the economic analysis of non stationary time series and the business cycle. Econometrica, 57, 357-384. http://dx.doi.org/10.2307/1912559

Hamilton, J. D., \& Lin, G. (1996). Stock market volatility and the business cycle. Journal of Applied Econometrics, 11 , 573-593. http://dx.doi.org/10.1002/(SICI)1099-1255(199609)11:5<573::AID-JAE413>3.0.CO;2-T

Harding, D., \& Pagan, A. (2006). Synchronization of cycles. Journal of Econometrics, 132, 59-79. http://dx.doi.org/10.1016/j.jeconom.2005.01.023

Ismail, M. T., \& Isa, Z. (2008). Identifying Regime Shifts in Malaysian Stock Market Returns. International Research Journal of Finance and Economics, 15, 44-57. 
Jermann, U., \& Quadrini, V. (2012). Macroeconomic effects of financial shocks. American Economic Review, 102(1), 238-271. http://dx.doi.org/10.1257/aer.102.1.238

Kanas, A., \& Ioannidis, C. (2012). Causality from real stock returns to real activity: evidence of regime-dependence. International Journal of Economics, 15(2), 180-197.

Krolzig, H. M. (2001). Markov-Switching Procedures for Dating the Euro-zone Business Cycle. Quarterly Journal of Economic Research, 3, 339-351.

Layton, A. P., \& Smith, D. R. (2007). Business Cycle Dynamics with Duration Dependence and Leading Indicators. Journal of Macroeconomics, 29, 855-875. http://dx.doi.org/10.1016/j.jmacro.2006.02.003

Levine, R., \& Zervos, S. (1996). Stock Market Development and Long-Run Growth. World Bank Economic Review, 10(2), 323-339. http://dx.doi.org/10.1093/wber/10.2.323

Omet, G., Khasawneh, M., \& Khasawneh, J. (2002). Efficiency tests and volatility effects: evidence from the Jordanian stock market. Applied Economics Letters, 9(12), 817-821. http://dx.doi.org/10.1080/13504850210161931

Stiglitz, J. E., Jaramillo-Vallejo, J., \& Park, Y. C. (1993). The role of the state in financial markets. Paper presented at the Annual Conference on Development Economics Supplement.

Turner, M. C., Startz, R., \& Nelson, C. F. (1989). A Markov model of heteroskedasticity, risk, and learning in the stock market. Journal of Financial Economics, 25, 3-22. http://dx.doi.org/10.1016/0304-405X(89)90094-9

$\mathrm{Vu}, \mathrm{N}$. T. (2014). Stock market volatility and international business cycle dynamics: Evidence from OECD economies. Journal of International Money and Finance, Forthcoming, 1-15.

Walter, C. (1996). Une histoire du concept d'efficience sur les marchés financiers. Annales. Histoire, Sciences Sociales, 51(4), 873-905. http://dx.doi.org/10.3406/ahess.1996.410892

\section{Copyrights}

Copyright for this article is retained by the author(s), with first publication rights granted to the journal.

This is an open-access article distributed under the terms and conditions of the Creative Commons Attribution license (http://creativecommons.org/licenses/by/3.0/). 